ISSN 0258-7122 (Print), 2408-8293 (Online)

Bangladesh J. Agril. Res. 43(4): 631-645, December 2018

\title{
DESIGN AND DEVELOPMENT OF A POWER GROUNDNUT SHELLER
}

\author{
M. A. HoQUE ${ }^{1}$, M. Z. HossAin ${ }^{2}$ AND M. A. $\operatorname{HosSAIN}^{3}$
}

\begin{abstract}
In Bangladesh groundnut shelling is done manually which is laborious, time consuming and costly. Shelling of groundnut pod with the help of mechanical power can be a probable solution of this problem. A power groundnut sheller was designed and fabricated in Farm Machinery and Postharvest Process Engineering (FMPE) Division, Bangladesh Agricultural Research Institute (BARI), Gazipur during 2011-13. The sheller was made of Mild Steel (MS) angle bar, MS flat bar, MS rod, MS sheet, MS sieve, rubber pad etc. The shelling capacities of power groundnut sheller were 110 and $115 \mathrm{~kg} / \mathrm{h}$ for Dhaka-1 and BARI Badam-8, respectively. Average breakage of groundnut kernel was $2 \%$ at $7.5 \%$ moisture content (wb). The maximum and minimum unshelled pods were about12.4\% and 9.18\% for Dhaka -1 and BARI Badam-8, respectively. The shelling efficiency of the power groundnut sheller for Dhaka-1 and BARI Badam- 8 were 86.6 and $88.82 \%$ respectively at $11.5 \%$ moisture content (wb). Winnowing efficiency was found to be $99 \%$ in the power groundnut sheller. The use of power groundnut sheller can reduce the cost of shelling by $76 \%$ over the manual groundnut sheller. This power groundnut sheller is recommended for shelling of groundnut at farm level and small industry level in Bangladesh.
\end{abstract}

Keywords: Groundnut, Power Sheller, Design, Fabrication and Performance.

\section{Introduction}

In Bangladesh, groundnut (Arachis hypogaea L.) is one of the important crops which can be cultivated round the year. The total cultivated area of groundnut was 35,726 ha with the total production of 62,264 t (BBS, 2016). Groundnut is the sixth most important oilseed crop in the world (Naim et al., 2010). Its worldwide production is more than 10 million tons per year (Bano and Negi, 2017). Developing countries constitute $97 \%$ of the global area and $94 \%$ of the global production of this crop (FAO, 2011). Groundnut kernel is contained in the pod which usually grown underground. The pod is harvested by hand or by a hoe. Sometimes, they are harvested by country plough. Later the pod is washed, dried and shelled or stored.

Shelling of the pod is laborious, time consuming and cost involving operation. Traditionally groundnut pods are shelled through manual operation in

${ }^{1}$ Senior Scientific Officer, ${ }^{2}$ Scientific Officer and ${ }^{3}$ Principle Scientific Officer, FMP Engineering Division, Bangladesh Agricultural Research Institute, Gazipur-1701. 
Bangladesh. As a result, the shelling of groundnut pod has constituted a bottleneck to the large-scale production and processing of the crop. Shelling is one of the main constraints of groundnut production in Bangladesh. Shelling is the process of grains subtraction from pod, either by stripping, impact action and rubbing or any combination of these methods. In Bangladesh, shelling is usually done by pressing the pod between the thumb and the finger to break off the pods and release the seed. This method has low efficiency, time consuming, and has high demand of energy. In addition, the output per-man hour is very low.

Paramawati et al. (2006) noted that quick postharvest handling could reduce the contamination of aflatoxin on groundnut. When groundnuts are intended to be used as kernels, the peeling process needs to be conducted rapidly. They also stated that using machines in postharvest handling, processing of groundnut makes it free from aflatoxin contamination. Atiku et al. (2004) evaluated a groundnut sheller and reported that the moisture content, material feed and the interaction between them had significant effect on the quantity of shelled, unshelled and partially shelled pods as well as that of damaged seeds. Winnowed chaffs at $1 \%$ level of significance and winnowing efficiencies decreased while percentage of partially shelled and unshelled pods increased with increase in moisture content and feed rate. The maximum shelling and winnowing efficiencies were 80 and $79.5 \%$, respectively at the moisture content of $5 \%$ (wb) over a feed rate of $93.6 \mathrm{~kg} / \mathrm{h}$. The Percentage of seed damage increased with increase in moisture content between 5 and $10 \%(\mathrm{wb})$ to a maximum value of $38 \%$ and decreased with further increase in moisture content. The broken pods are susceptible to aflatoxin contamination hence minimum breakage is desirable (Rahmianna et al., 2015).

A good numbers of groundnut sheller machines are available in the market but they are large in size, costly and not suitable for domestic applications. They are suitable for industrial applications where mass production is required (Walke et al., 2017). In most of the cases the postharvest manual shelling operation of groundnut is done by women in rural area. BARI has developed a manual groundnut sheller in 2010-11 (Hoque et al., 2011). Power groundnut sheller was designed and fabricated executing the recommendation after development of manual sheller (Hoque et al., 2011). Operation of manual groundnut sheller was generating human drudgery for which it required 5 minutes rest after every 10-15 minutes operation. The manual sheller was also unable to separate husk from the grain and also unable to clean the grain from the unshelled groundnut. At present, there is no power groundnut sheller at farm level in Bangladesh. The development of small, power sheller have a good scope for shelling of groundnut at farm level and small-scale processing level. Therefore, this study has been undertaken to develop a suitable power groundnut sheller for farm level and 
industrial uses. The machine was designed having the strength and stability of materials of construction in mind so as to meet up with the required standard. (Fadele and Aremu, 2016; Pradhan et al., 2010). The main objectives of this study were to design and development of a power groundnut sheller and to test the performance of the sheller.

\section{Materials and Methods}

\section{Design and fabrication}

A power groundnut sheller was designed for shelling about $100 \mathrm{~kg}$ groundnut per hour. The engineering drawing of the sheller was drawn with SolidWorks Software 2013 (Fig. 1) and fabricated (as shown in Fig. 2) at the workshop of the Farm Machinery and Postharvest Process Engineering Division of Bangladesh Agricultural Research Institute, Joydebpur, Gazipur during 2011-2012. It was made of locally available materials. Mild Steel (MS) angle bar, MS flat bar, MS rod, MS sheet, MS shaft, rubber pad, ball-bearing, $0.37 \mathrm{~kW}$ electric motor and other small parts were used to fabricate the groundnut sheller. Design and drawing of various parts are necessary for fabrication of quality machine. Different parts of the power maize Sheller are described below. The detailed specification of the groundnut sheller is given in Table 1.

Table 1. Specifications of power groundnut sheller

\begin{tabular}{l|l}
\hline Item & Specification \\
\hline Length (mm) & 1060 \\
Width (mm) & 410 \\
Height (mm) & 1010 \\
Weight (kg) & 74 \\
Length of shelling arm (mm) & 520 \\
Concave inner length (mm) & 460 \\
Concave radius (mm) & 260 \\
Rubber pad size (mm) & $220 \times 60 \times 37$ \\
Sieve size (mm) & $10 \times 24$ \\
Hopper capacity (kg) & $8-10$ \\
Clearance (mm) & $11-13$ \\
Mode of operation & Power operated \\
Source of power $(\mathrm{kW})$ & 0.37 \\
\hline
\end{tabular}




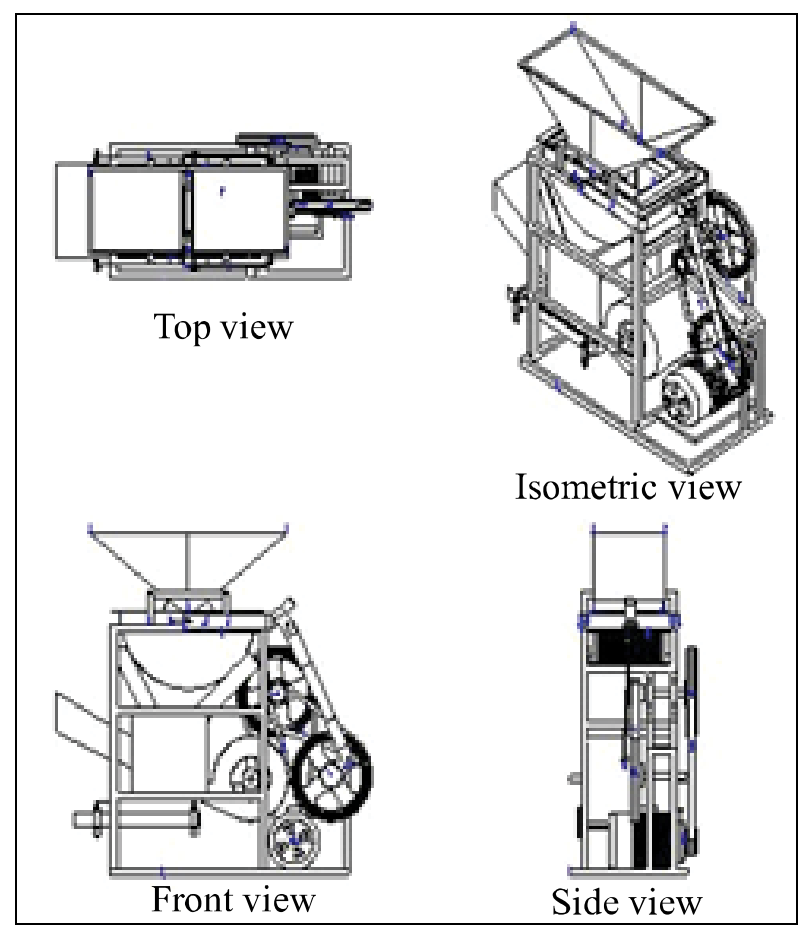

Fig. 1. Orthographic projections (OP) of power groundnut sheller.

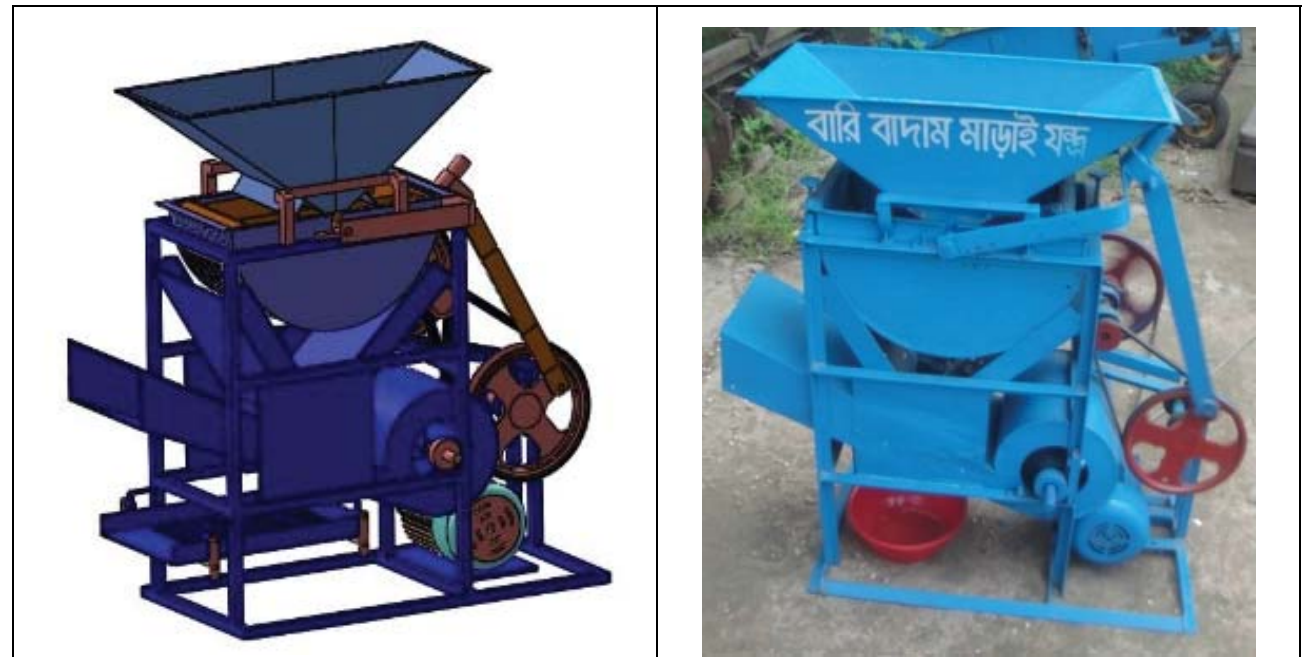

3D isometric view

Photographic view

Fig. 2. Isometric and photographic views of the power groundnut sheller. 
1. Hopper: The hopper of the sheller was fabricated with MS sheet. The sheller hopper was designed to hold $8-10 \mathrm{~kg}$ groundnut. Overall dimension of the hopper is $676 \times 260 \times 235 \mathrm{~mm}$ as shown in Fig. 3.

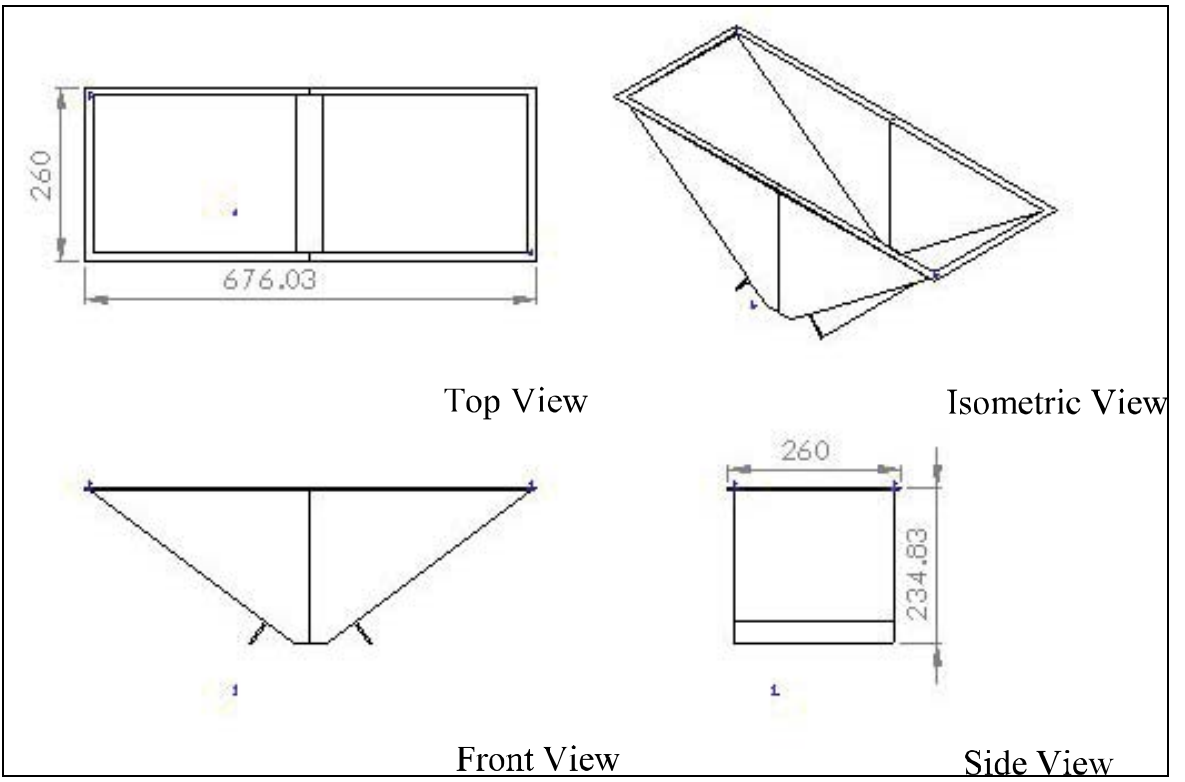

Fig.3. Orthographic projections (OP) of hopper.

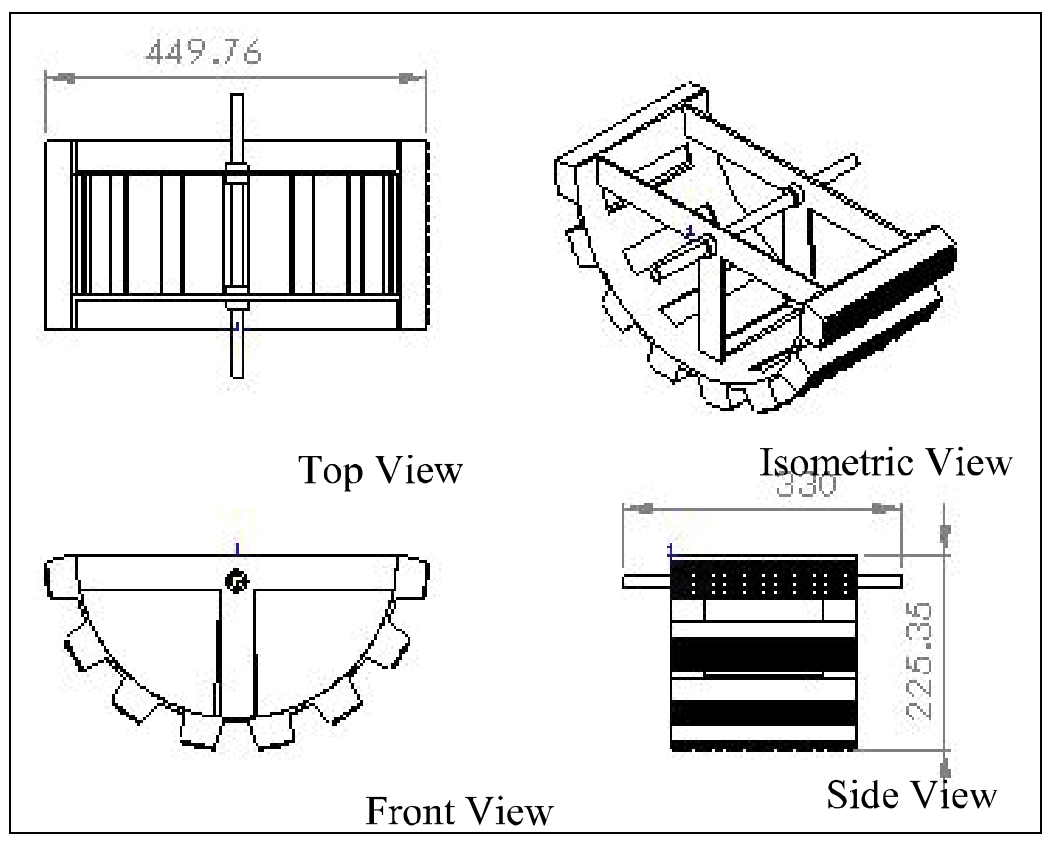

Fig.4. OP of pressing component. 


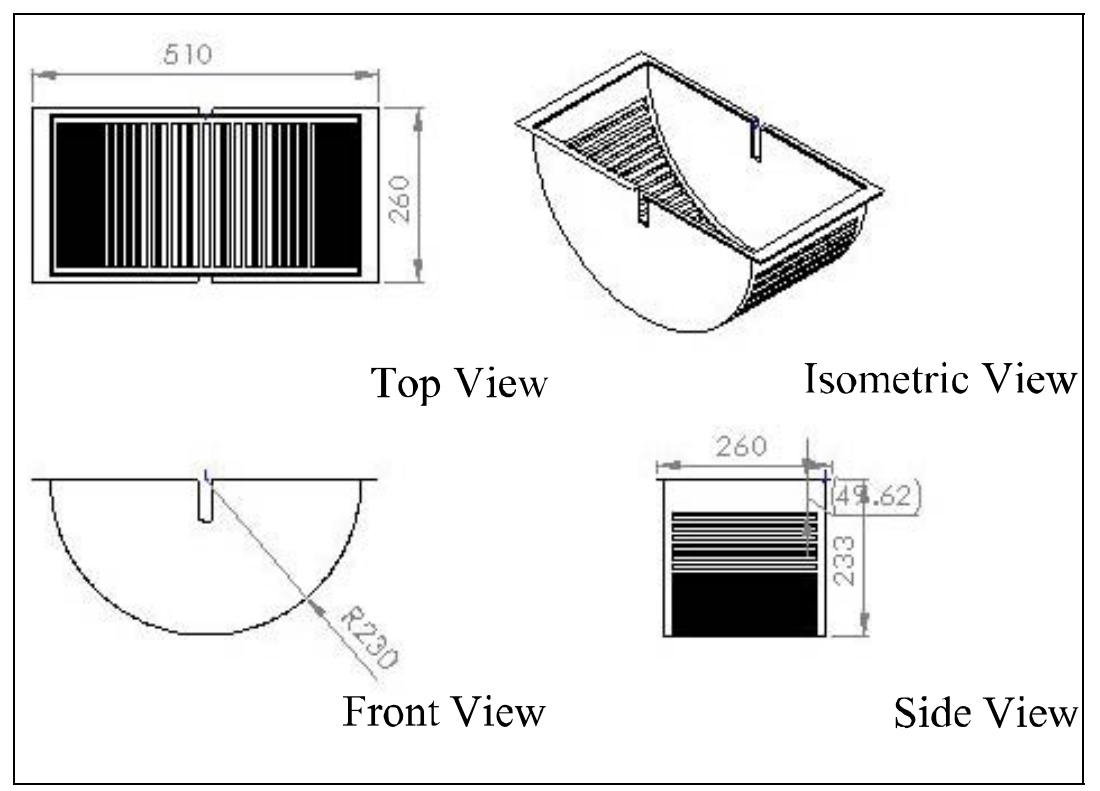

Fig.5. OP of shelling concave.

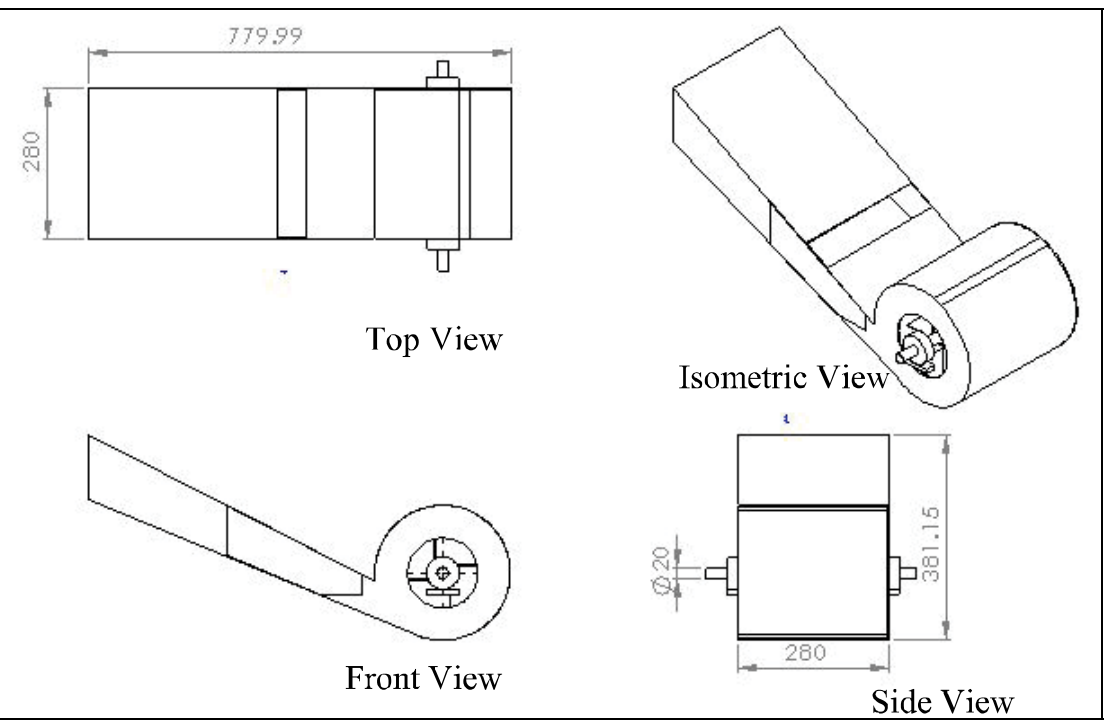

Fig.6. OP of blower.

2. Pressing component: A half cylinder rotating pressing component was fabricated (Fig. 4). Eight pressing arms was uniformly distributed on the peripheral diameter of the cylinder. Soft rubber sheet having zigzag bits were used for making rubber pad to press on the groundnut. This part 
was reciprocating within the shelling concave powered by $0.37 \mathrm{~kW}$ electric motor. Clearance between rubber pad and shelling concave can be adjusted using screw.

3. Shelling concave: Half circular threshing concave with $230 \mathrm{~mm}$ radius was fabricated with MS sheet and flat bar (Fig. 5). Width of the concave was $260 \mathrm{~mm}$. The flat bars were uniformly spaced at $11-13 \mathrm{~mm}$ interval over the peripheral diameter of the threshing cylinder. Selection of the opening depends on variety of groundnut.

4. Blower: A blower (Fig. 6) was fabricated with MS sheet which was operated with the same $0.37 \mathrm{~kW}$ electric motor. The speed of the fan was $450 \mathrm{rpm}$. Due to high velocity air flow, the shelled husk of the groundnut was separated from the kernel during falling from shelling concave.

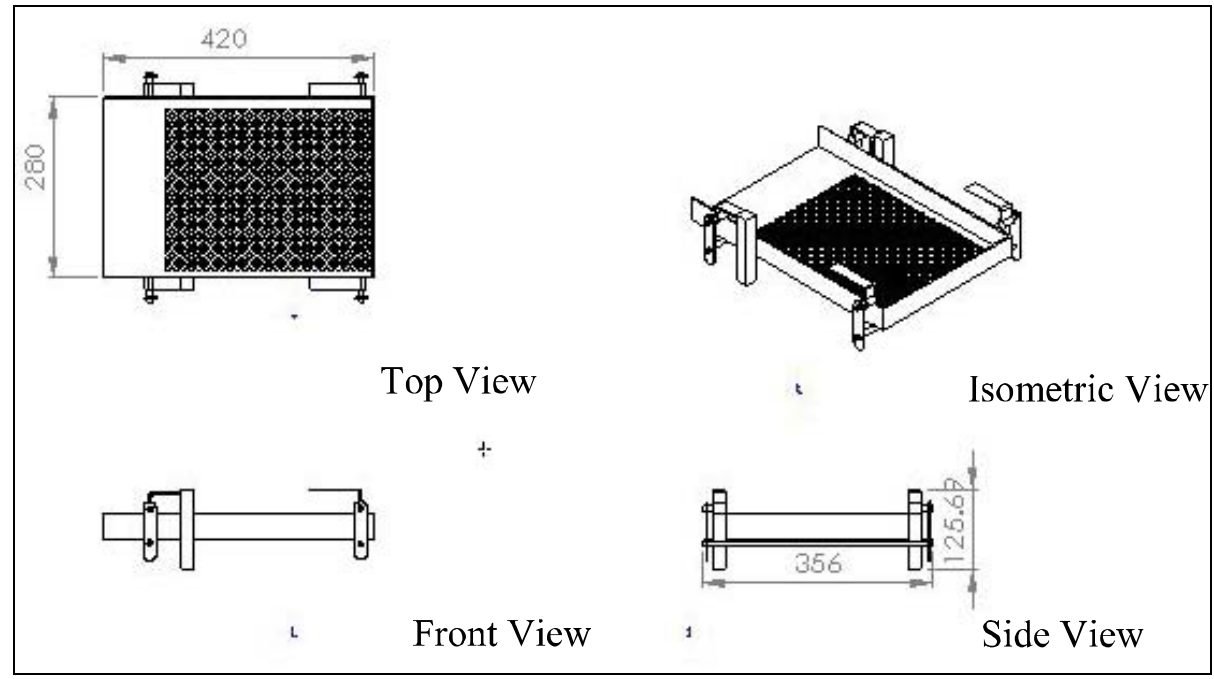

Fig.7. OP of cleaning sieve

5. Cleaning sieve: A sieve having $9 \mathrm{~mm}$ diameter hole was used for cleaning of the groundnut kernel. The sieve was operated with a cam to move in the horizontal motion. The dimension of the sieve was $420 \mathrm{x}$ $280 \mathrm{~mm}$ as shown in Fig. 7.

\section{Operation Principle}

The machine was operated with a single phase electric motor. Unshelled groundnut pod was fed in the feeding hopper. The sheller was started with a switch after giving due connection of this sheller with domestic electric line of $220 \mathrm{~V}$ of AC power. With the electric motor, the movable threshing pad was operated within threshing cylinder. The groundnut was inserted in the threshing cylinder and after shelling fell into the sieving tray. The broken husk of 
groundnut was separated with air blow which was flown from the blower. The shelled grain was separated with the sieve by shaking with a rotating cam.

\section{Experimental Procedure}

The length, width and thickness of Dhaka- 1 and BARI Badam-8 variety were measured with slide calipers of $0.02 \mathrm{~mm}$ accuracy. Randomly selected 50 samples from each variety were taken for the measurement. The length, width and thickness of whole groundnut and kernel were measured. Performance evaluation of the groundnut sheller was done with replicated experiments during 2012-13 in the laboratory of Farm Machinery and Postharvest Process Engineering Division, BARI, Gazipur. The performance of the power groundnut sheller and manual groundnut sheller (Fig. 8) was tested with Dhaka-1 and BARI Badam-8 collected from local market of Gazipur Sadar.

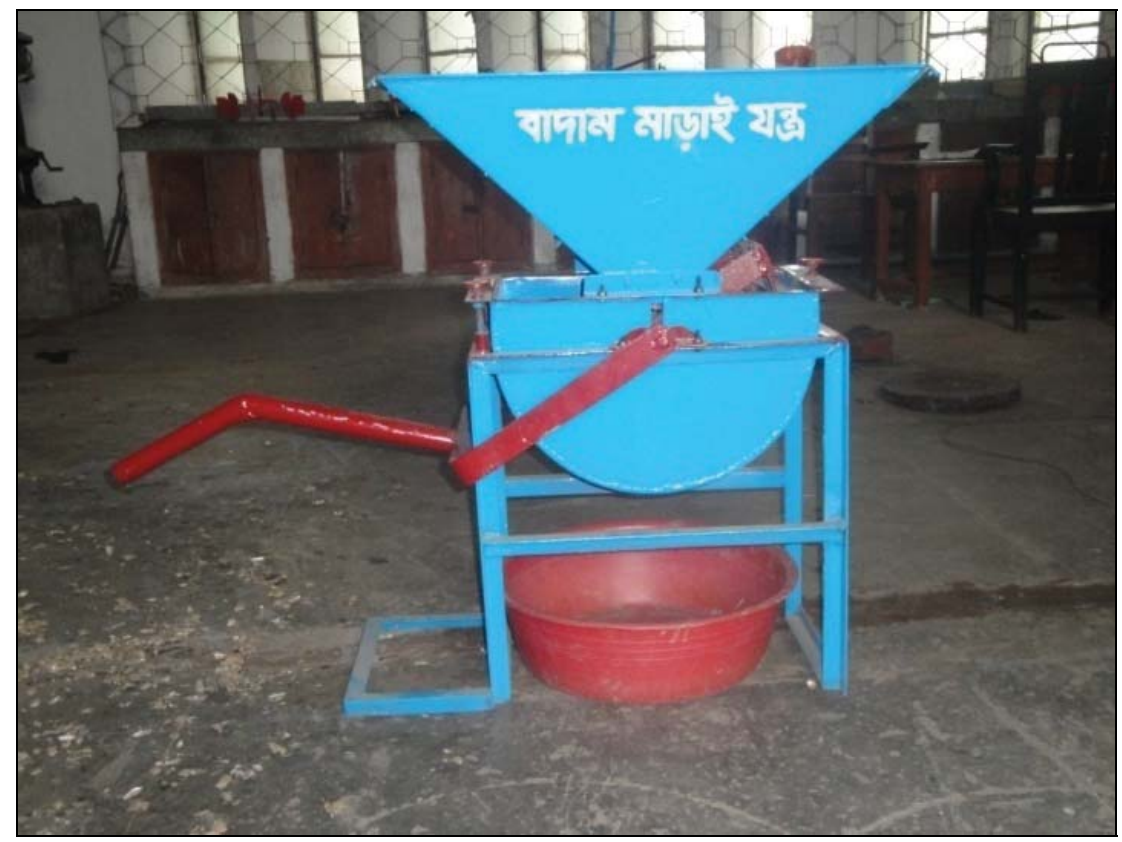

Fig.8. A photographic view of the manual groundnut sheller.

Moisture content of the groundnut was measured by oven dry method drying for 72 hours at $103^{\circ} \mathrm{C}$ (Koushkaki et al. 2017). Initial moisture content of the groundnut was around 7\% which was reduced by oven and then packet in poly bags. The moisture content of the groundnut during testing was maintained at around 7.50\% (wb) since Kushwah et al. (2016) and Oluwole et al. (2007) found better dehulling efficiency and crackability of groundnut with similar moisture content. Sample size of each batch was $10 \mathrm{~kg}$. The testing was replicated five times for each variety. The weight of shelled grain, weight of unshelled grain, 
weight of cracked grain, frequency of oscillation of the shelling pad, time of operation and moisture content of grain were recorded during testing of the groundnut sheller. Capacity, breakage and efficiency of the groundnut sheller were calculated. The power groundnut sheller was then tested at two upazilla (Nagarbari and Sujanagar) of Pabna district. The machine was evaluated with Dhaka-1 and BARI Badam-8 similarly. The following parameters were calculated using the standard formula as given below

i) Shelling capacity, $\mathrm{S}_{\mathrm{c}}=\frac{60 \mathrm{~W}_{2}}{\mathrm{~T}}$

Where,

$\mathrm{S}_{\mathrm{c}}=$ Shelling capacity, $\mathrm{kg} / \mathrm{h}$

$\mathrm{W}_{\mathrm{s}}=$ Weight of shelled grain, $\mathrm{kg}$

$\mathrm{T}=$ Operating time, minutes

ii) Breakage percentage, $\mathrm{Br}=\frac{\mathrm{W}_{\mathrm{b}}}{\mathrm{W}_{\mathrm{s}}} \times 100$

Where,

$\mathrm{B}_{\mathrm{r}}=$ Breakage percentage

$\mathrm{W}_{\mathrm{b}}=$ Weight of broken grain, $\mathrm{kg}$

iii) Unshelled grain, $\mathrm{U}_{\mathrm{ng}}=\frac{\mathrm{W}_{\mathrm{u}}}{\mathrm{W}_{\mathrm{g}}} \times 100$

Where,

$\mathrm{U}_{\mathrm{ng}}=$ Unshelled grain, \%

$\mathrm{W}_{\mathrm{u}}=$ Weight of unshelled groundnut, $\mathrm{kg}$

$\mathrm{W}_{\mathrm{g}}=$ Weight of total feed, $\mathrm{kg}$

iv) Shelling efficiency, $W_{s}=100-B_{r}-U_{n g}$

v) Winnowing efficiency, $E_{s}=\frac{W_{c}}{W_{c}-W_{h}}$

Where,

$\mathrm{E}_{\mathrm{c}}=$ Winnowing efficiency, \%

$\mathrm{W}_{\mathrm{c}}=$ Weight of cleaned groundnut, $\mathrm{kg}$

$\mathrm{W}_{\mathrm{h}}=$ Weight of husk mixed with cleaned kernel, kg 
vi) Separation efficiency, $E_{s}=\frac{W_{f}}{W_{t}-W_{u}}$

$$
\begin{aligned}
& \text { Where, } \\
& \mathrm{W}_{\mathrm{f}}=\text { Weight of the fresh grain in pan, kg } \\
& \mathrm{W}_{\mathrm{t}}=\text { Weight of total grain in pan, } \mathrm{kg} \\
& \mathrm{W}_{\mathrm{u}}=\text { Weight of unshelled grain in pan, kg }
\end{aligned}
$$

\section{Results and Discussion}

The length, width and thickness of pod of Dhaka- 1 variety were $20.00 \pm 2.72$, $11.20 \pm 1.24,10.46 \pm 0.99 \mathrm{~mm}$, respectively (Fig. 9). The pod length, width and thickness of BARI Badam-8 were 23.98 $\pm 3.20,12.44 \pm 1.09,11.88 \pm 1.20$ mm, respectively (Fig. 10). Kernel length, width and thickness of Dhaka-1 and BARI Badam-1 were 13.27 $\pm 1.55,8.59 \pm 1.02,8.18 \pm 0.99 \mathrm{~mm}$ and $11.24 \pm 1.13,8.02 \pm 1.09,7.12 \pm 0.83 \mathrm{~mm}$, respectively. Based on pod and kernel size, the opening of the threshing cylinder sieve was selected as $11 \mathrm{~mm}$ for which most of the pod of the both variety were threshed with minimum breakage of grain.

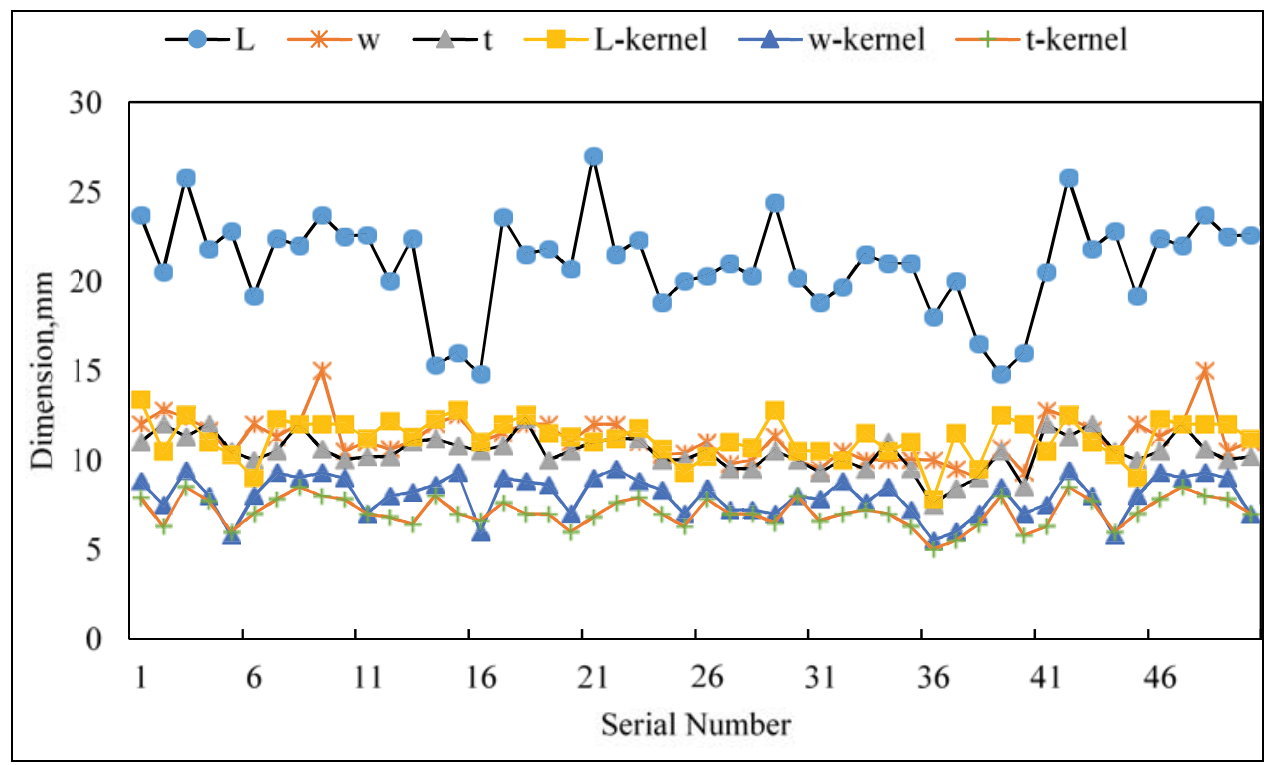

Fig.9. Length (L), width (W) and thickness (T) of some sample of Dhaka-1 groundnut. 


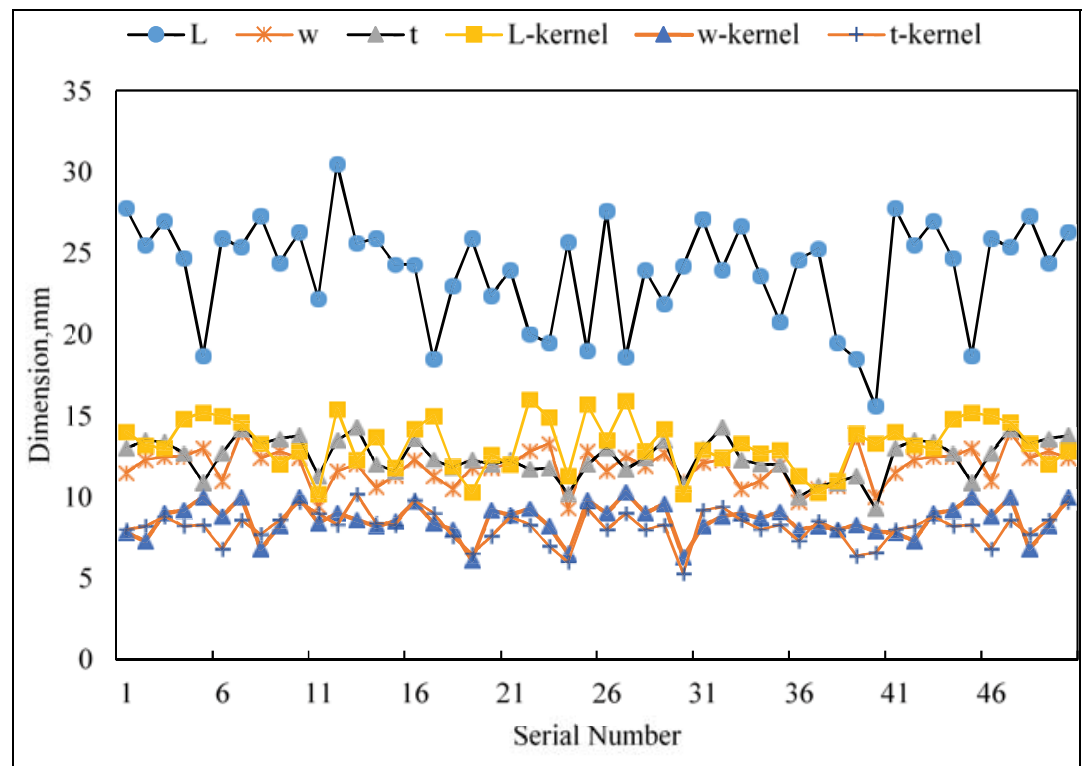

Fig.10. Length (L), width (W) and thickness (T) of some sample of BARI Badam-8 groundnut.

The developed groundnut sheller was capable to work continuously and facilitate winnowing. Moreover, this can separate unshelled groundnut from the shelled groundnut using same with simple $0.37 \mathrm{~kW}$ electric motor. Comparative performance of the power groundnut sheller and manual sheller for Dhaka-1 and BARI Badam-8 is shown in Table 2. It was observed from Table 2 that the shelling capacities of power groundnut sheller were 110 and $114.72 \mathrm{~kg} / \mathrm{h}$ for Dhaka-1 and BARI Badam-8, respectively whereas 84.50 and $80 \mathrm{~kg} / \mathrm{h}$ for manual sheller. Similar and even less capacity was found by Atiku et al. (2004). The shelling capacity of the manual sheller was lower than that of power groundnut sheller due to less stroke number per minute. Higher breakage percentages of the manual sheller were observed for both Dhaka-1 and BARI Badam-8 than those of power sheller. It might be due to longer stroke length in manual sheller. Average breakage of groundnut pod was found to be $2 \%$ at $11.5 \%$ moisture content (wb) in the lab test. The maximum and minimum unshelled percentage in power sheller was found to be $12.4 \%$ for Dhaka-1 and 9.18\% for BARI Badam-8, respectively. Unshelled nuts were found due to less diameters of groundnut than the opening of the shelling sieve $(10 \mathrm{~mm})$. Unshelled percentage of the tested power sheller was found more for Dhaka- 1 since the diameter of the grain was less than opening of the shelling concave. This unshelling could be reduced by changing shelling concave with less opening. It was also found that the shelling efficiency of the power groundnut sheller for Dhaka-1 and BARI Badam- 8 were 86.6 and $88.82 \%$, respectively at $11.5 \%$ moisture content (wb) which is similar with Ugwuoke et al. (2014). Winnowing efficiency of the power groundnut sheller was found to be $99 \%$ which was acceptable as reported by (Atiku et al., 
2004). Separation of fresh shelled kernel from unshelled groundnut was found from power groundnut sheller and separation efficiency was 97 and $98 \%$ for Dhaka-1 and BARI Badam-8 variety, respectively.

Table 2. Comparative performance of the power groundnut sheller and manual sheller for Dhaka-1 and BARI Badam-8 tested in the laboratory of FMPE Division, BARI, Gazipur

\begin{tabular}{l|ccc|c}
\hline \multirow{2}{*}{\multicolumn{1}{c}{ Parameters }} & \multicolumn{2}{c|}{ Dhaka-1 } & \multicolumn{2}{c}{ BARI Badam-8 } \\
\cline { 2 - 5 } & Power & Manual & Power & Manual \\
\hline Moisture content (wb, \%) & 7.50 & 7.49 & 7.51 & 7.52 \\
Weight of sample (kg) & 10 & 10 & 10 & 10 \\
Time required, minutes & 5.5 & 7.1 & 5.23 & 7.5 \\
Stroke (no/minutes) & 100 & 50 & 98 & 43 \\
Shelling capacity (kg/h) & 110 & 84.50 & 114.72 & 80 \\
Broken grain (\%) & 1.00 & 2.00 & 2.00 & 2.00 \\
Unshelled grain (\%) & 12.40 & 13.00 & 9.18 & 10.85 \\
Shelling efficiency (\%) & 86.6 & 85 & 88.82 & 87.15 \\
Winnowing efficiency (\%) & 99 & 0 & 99 & 0 \\
Separation efficiency (\%) & 97 & 0 & 98 & 0 \\
\hline
\end{tabular}

Performance of power groundnut sheller at Pabna is given in Table 3. Shelling capacities of the groundnut sheller were found to be 124 and $128 \mathrm{~kg} / \mathrm{h}$ at Nagarbari and Sujanagar of Pabna district, respectively. Broken grain (4 to 5\%) and unshelled grain (13 to 15\%) were more in the field test than those of the laboratory test due to uneven size, non-graded sample and high moisture content of groundnut samples. Thus, the shelling efficiencies were $83 \%$ and $80.0 \%$ in Nagarbari and Sujanagar, respectively. Winnowing efficiency was found $100 \%$ in both the locations. However, farmers showed their interest in power operated groundnut sheller for confectionary purposes.

Table 3. Performance of power groundnut sheller for shelling Dhaka-1 groundnut in Pabna

\begin{tabular}{l|c|c}
\hline \multicolumn{1}{c|}{ Parameters } & Nagarbari & Sujanagar \\
\hline Weight of sample (kg) & 85 & 120 \\
Moisture content, (wb, \%) & 9.50 & 9.75 \\
Time required (minutes) & 41 & 56 \\
Stroke (no/minutes) & 100 & 100 \\
Shelling capacity (kg/h) & 124 & 128 \\
Broken grain (\%) & 04 & 05 \\
Unshelled grain (\%) & 13 & 15 \\
Shelling efficiency (\%) & 83 & 80 \\
Winnowing efficiency (\%) & 100 & 100 \\
\hline
\end{tabular}




\section{Financial analysis}

Cost analysis was done after the satisfactory performance evaluation of the power groundnut sheller. Different costs of the power and manual groundnut shellers are shown in Table 4 . The price of the power and manual groundnut sheller was Tk. 25000 and Tk. 7500, respectively. The cost of the groundnut shelling was $590 \mathrm{Tk} / \mathrm{t}$ for power groundnut. On the other hand, shelling, cost by manual groundnut sheller was $2450 \mathrm{Tk} / \mathrm{t}$. Therefore, the use of power groundnut sheller would reduce the cost of shelling by $76 \%$ over the manual groundnut sheller.

Table 4. Different costs of the power and manual groundnut shellers

\begin{tabular}{|c|c|c|c|}
\hline \multirow{2}{*}{$\begin{array}{l}\text { Sl. } \\
\text { No. }\end{array}$} & \multirow{2}{*}{ Cost factors and items } & \multicolumn{2}{|c|}{ Costs } \\
\hline & & Power & Manual \\
\hline 1 & Price of the groundnut sheller (Tk/unit) & 25000 & 7500 \\
\hline 2 & Life of the groundnut sheller (Years) & 5 & 5 \\
\hline 3 & Annual use (Hours) & 240 & 240 \\
\hline \multirow[t]{6}{*}{4} & Annual fixed cost & & \\
\hline & a) Depreciation (Tk/yr) & 4500 & 1350 \\
\hline & b) Interest (12\%) (Tk/yr) & 1375 & 412.5 \\
\hline & c) Repair, maintenance and shelter ( $\mathrm{Tk} / \mathrm{yr})$ & 875 & 262.5 \\
\hline & Total fixed cost (Tk/yr) & 6750 & 2025 \\
\hline & Total fixed cost (Tk/h) & 28.13 & 8.44 \\
\hline \multirow[t]{6}{*}{5} & Operating cost & & \\
\hline & a) Electricity $(\mathrm{Tk} / \mathrm{h})$ & 2.16 & \\
\hline & b) Labour for shelling $(\mathrm{Tk} / \mathrm{h})$ & 37.50 & \\
\hline & c) labour for winnowing $(\mathrm{Tk} / \mathrm{h})$ & 0 & $\begin{array}{l}3 / .50 \\
37.50\end{array}$ \\
\hline & $\begin{array}{l}\text { d) labour for separation of unshelled pods } \\
(\mathrm{Tk} / \mathrm{h})\end{array}$ & 0 & 112.50 \\
\hline & Total operating cost $(\mathrm{Tk} / \mathrm{h})$ & 39.66 & 187.50 \\
\hline 6 & Total cost $(\mathrm{Tk} / \mathrm{h})$ & 67.79 & 195.94 \\
\hline 8 & Shelling cost $(\mathrm{Tk} / \mathrm{t})$ & 590 & 2450 \\
\hline
\end{tabular}

\section{Conclusion}

The power groundnut sheller was operated without any trouble of the machine. The shelling capacities of power groundnut sheller were 110 and $115 \mathrm{~kg} / \mathrm{h}$ for Dhaka- 1 and BARI Badam- 8 , respectively. The maximum breakage of groundnut was found to be $2 \%$ at $11.5 \%$ moisture content (wb) in laboratory test at FMPE Division, BARI, Gazipur. The maximum and minimum unshelled percentage in power sheller was found to be $12.4 \%$ for Dhaka-1 and 9.18\% for BARI Badam-8, respectively. The shelling efficiency of the power groundnut sheller for Dhaka-1 and BARI Badam-8 were 86.6 and $88.82 \%$, respectively at $7.5 \%$ moisture content (wb). Winnowing efficiency was found to be $99 \%$ in the power 
groundnut sheller. Shelling capacities of the groundnut sheller were found to be 124 and $128 \mathrm{~kg} / \mathrm{h}$ at Nagarbari and Sujanagar of Pabna district, respectively. Broken grain (4 to 5\%) and unshelled grain (13 to 15\%) were more in the field test than those of the laboratory test due to uneven size and high moisture content of groundnut samples. The performance of the groundnut could be improved by feeding uniform sized pods. The use of power groundnut sheller can reduce the cost of shelling by $76 \%$ over the manual groundnut sheller.

\section{Acknowledgement}

The authors are highly grateful to Farm Machinery and Postharvest Process Engineering Division, Bangladesh Agricultural Research Institute, Gazipur for financial and technical support.

\section{References}

Atiku, A., N. Aviara and M. Haque. 2004. Performance evaluation of a bambara groundnut sheller. Agricultural Engineering International: the CIGR Journal of Scientific Research and Development. Manuscript PM 04 002(4):1-18.

Bano, S. and Y.S. Negi. 2017. Studies on cellulose nano crystals isolated from groundnut shells, Carbohydrate Polymers. 157: 1041-1049. http://dx.doi.org/10.1016/j.carbpol. 2016.10.069.

BBS, 2016. Statistical Pocket Book. Bangladesh Bureau of Statistics. Peoples Republic of Bangladesh. Pp. 150.

Fadele, O.K. and A.K. Aremu. 2016. Design, construction and performance evaluation of a Moringa oleifera seed shelling machine. Engineering in Agriculture, Environment and Food, 9: 250-256. http://dx.doi.org/10.1016/j.eaef.2016.01.002.

FAO, 2011. Food and Agriculture Organization of the United Nations, http://www.fao.org/home/en/

Hoque, M.A., M.A. Hossain, M.A. Wohab, M.N. Amin and M.S. Hassan. 2011. Design and development of manual groundnut sheller. Annual Research Report of Farm Machinery and Postharvest Process Engineering Division, BARI, Gazipur. Pp. 1317.

Ibrahim, U.B.T., H. Ayinde and Dauda Mukhtar. 2013. Socio-economic factors affecting groundnut production in sabongari local government state, Nigeria. International Journal of Food and Agricultural Economics. 1(1): 41-48.

Koushkaki, H.R., A.N. Moghadami, D. Zare and G. Karimi 2017. Experimental and theoretical investigation of hot air-infrared thin layer drying of corn in a fixed and vibratory bed dryer. Engineering in Agriculture, Environment and Food. 10: 191197.

Kushwah, O.S., B.S. Gholap and M. Singh. 2016. Studies on effect of moisture content on dehulling efficiency of groundnut testa remover for groundnut kernels. Ecology, Environment and Conservation paper. 22(2): 791-796.

Naim, A.M.E., M.A. Eldouma and A.E. Abdalla. 2010. Effect of weeding frequencies and plant population on vegetative growth characteristic in groundnut (Arachis 
hypogaea L.) in North Kordofan of Sudan. International Journal of Applied Biology and Pharmaceutical Technology. 1(3): 1188-93.

Oluwole, F.A., A.T. Abdulrahim and R.K. Olalere. 2007. Effect of moisture content on crackability of bambara groundnut using a centrifugal cracker. Int. Agrophysics. 21: 179-184.

Paramawati, R, P. Widodo, U. Budiharti and Handaka. 2006. The role of postharvest machineries and packaging in minimizing aflatoxin contamination in peanut. Indonesian Journal of Agricultural Science. 7(1):15-19.

Pradhan, R.C., S.N. Naik, N. Bhatnagar and V.K. Vijay. 2010. Design, development and testing of hand- operated decorticator for jatropha fruit. Appl. Energy. 87: 762-768.

Rahmianna, A.A., J. Purnomo and E. Yusnawan. 2015. Assessment of groundnut varietal tolerant to aflatoxin contamination in indonesia. The First International Symposium on Food and Agro-biodiversity (ISFA 2014). Procedia Food Science. 3 (2015): 330 339.

Ugwuoke, I.C., O.J. Okegbile and I.B. Ikechukwu. 2014. Design and fabrication of groundnut shelling and separating machine. International Journal of Engineering Science Invention. 3(4): 60-66.

Walke, T., P. Gadge, G. Gohate and R. Banpurkar. 2017. Design and fabrication of groundnut sheller machine. International Research Journal of Engineering and Technology (IRJET). 04(03): 1606-1610. 
